EPJ Web of Conferences 45, 01100 (2013)

DOI: $10.1051 /$ epjconf/20134501100

(c) Owned by the authors, published by EDP Sciences, 2013

\title{
Investigation of Absorption Cooling Application Powered by Solar Energy in the South Coast Region of Turkey
}

\author{
O. Babayigit ${ }^{1, a}$, M. H. Aksoy ${ }^{2}$, M. Ozgoren ${ }^{2}$ and O. Solmaz ${ }^{3}$ \\ ${ }^{1}$ Selcuk University, Hadim Vocational School, Machine and Metal Technologies Department, Konya, Turkey. \\ ${ }^{2}$ Selcuk University, Engineering Faculty, Mechanical Engineering Department, Konya, Turkey. \\ ${ }^{3}$ Selcuk University, Technical Education Faculty, Mechanical Education Department, Konya, Turkey.
}

\begin{abstract}
In this study, an absorption system using ammonia-water $\left(\mathrm{NH}_{3}-\mathrm{H}_{2} \mathrm{O}\right)$ solution has been theoretically examined in order to meet the cooling need of a detached building having $150 \mathrm{~m}^{2}$ floor area for Antalya, Mersin and Mugla provinces in Turkey. Hourly dynamic cooling load capacities of the building were determined by using Radiant Time Series (RTS) method in the chosen cities. For the analysis, hourly average meteorological data such as atmospheric air temperature and solar radiation belonging to the years 1998-2008 are used for performance prediction of the proposed system. Thermodynamic relations for each component of absorption cooling system is explained and coefficients of performance of the system are calculated. The maximum daily total radiation data were calculated as $7173 \mathrm{~W} / \mathrm{m}^{2}$ day on July $15,7277 \mathrm{~W} / \mathrm{m}^{2}$ day on July 19 and $7231 \mathrm{~W} / \mathrm{m}^{2}$ day on July 19 for Mersin, Antalya and Mugla, respectively on the $23^{\circ}$ toward to south oriented panels from horizontal surface. The generator operating temperatures are considered between 90 $130^{\circ} \mathrm{C}$ and the best result for $110^{\circ} \mathrm{C}$ is found the optimum degree for maximum coefficient of performance (COP) values at the highest solar radiation occurred time during the considered days for each province. The COP values varies between 0.521 and 0.530 for the provinces. In addition, absorber and condenser capacities and thermal efficiency for the absorption cooling system were calculated. The necessary evacuated tube collector area for the different provinces were found in the range of $45 \mathrm{~m}^{2}$ to $47 \mathrm{~m}^{2}$. It is shown that although the initial investment cost is higher for the proposed absorption cooling system, it is economically feasible because of its lower annual operation costs and can successfully be operated for the considered provinces.
\end{abstract}

\section{Introduction}

Energy plays an important role in supporting our daily life, economic development and every human activity. Energy systems are complex as they involve various economic, technical, environmental, legal and political factors [1,2]. Due to the limitation of fossil energy resources, the impact on the environment and the human health problems during the last decades, there has been a growing interest on developing modeling and optimization strategies for many applications including cooling [3]. Solar energy is the most readily available source among renewable energy sources which can provide heat, light, hot water, electricity, and even cooling, for homes, businesses, and industry, especially in places where electricity is expensive or in short supply. With the use of solar energy, usage of conventional energy sources and its peak demand will be reduced [4]. The use of solar energy for cooling offers the advantage of energy availability that is correlated, to some degree, to the demand for cooling. This arrangement is especially interesting because the hours in which more solar radiation is available, are the hours with more cooling needs. Currently, one of the most commonly applied method is vacuum tube collectors to produce a hot fluid, which is used to drive a thermal chiller. Among the different thermal technologies, absorption systems offer readily available commercial equipment and new technological advances [5-8].

Absorption systems are similar to vapor-compression air conditioning systems but differ in the pressurization stage. In general an absorbent, on the low-pressure side, absorbs an evaporating refrigerant. The most usual combinations of fluids include lithium bromide-water $\left(\mathrm{LiBr}-\mathrm{H}_{2} \mathrm{O}\right)$ where water vapor is the refrigerant and ammonia-water $\left(\mathrm{NH}_{3}-\mathrm{H}_{2} \mathrm{O}\right)$ systems where ammonia is the refrigerant [9].

Turkey has high solar energy potential because of its location in the northern hemisphere with latitudes 36-42 ${ }^{\circ} \mathrm{N}$ and longitudes $26-45^{\circ} \mathrm{E}$. Consequently, it is of worth to investigate and conduct research on this solar energy source [10]. According to meteorological data which

a obabayigit@ selcuk.edu.tr 
were taken from Turkish State Meteorological Service, the yearly average solar-radiation is $3,6 \mathrm{kWh} / \mathrm{m}^{2}$ day, and the total yearly radiation period is 2610 hours [11]. While it seems an advantage for solar powered applications conversely it increased cooling requirement. Especially in the south coast cities of Turkey where are important touristic places and have considerable population cooling is very important due to indoor comfort conditions in summer season.

The literature review on solar absorption refrigeration cycles shows that a thermodynamic simulation can be performed in order to study and analyze the system. Some studies have been done in this area and have been considered extensively, but the effect of the generator temperature in a solar powered single absorption refrigeration system by meteorological solar data for a house usage depending on the cooling need has not been considered in detail. Some of the studies are given [1217] and cited therein.

In this study, an absorption system using ammoniawater $\left(\mathrm{NH}_{3}-\mathrm{H}_{2} \mathrm{O}\right)$ solution has been studied for Mugla Antalya and Mersin located along south coast in Turkey. This simulation was performed also in order to investigate the effect of the generator temperature over the COP and for absorption cooling system that uses solar energy as a primary source.

\section{Material and Methods}

In this study, an absorption system using ammonia-water $\left(\mathrm{NH}_{3}-\mathrm{H}_{2} \mathrm{O}\right)$ solution has been hourly examined with the help of thermodynamics laws. The system has been accepted working with an evacuated tube collector. For the analysis, meteorological data such as atmospheric air temperature and solar radiation between the years 19982008 of Mugla, Antalya and Mersin provinces in Turkey are used. Firstly, cooling load capacity of a detached house given in figure 1 for considered provinces are hourly calculated by using Radiant Time Series (RTS) Method during the maximum radiation occurrence day as of July 19 for Mugla and Antalya, July 15 for Mersin. Wall thickness of the building including brick, insulation and other layers was taken as $0.2 \mathrm{~m}$. It is assumed that the detached building is placed anywhere in the considered provinces. Also the hourly total heat gain of the sample building comprised of wall, window, human, illumination and devices were determined by using the RTS method. Details of this method were given by McQuiston et al [18] and ASHRAE [19].

A schematic view of the entire solar absorption refrigeration system is shown in figure 2 and the pressure-temperature diagram of the absorption cycle is presented in figure 3. Absorption cooling cycle consists mainly of solar collector, generator, evaporator, absorber, expansion valve separator, circulation pump and other small parts.

Figures 2 and 3 illustrate the main components and working principles of the absorption refrigeration cycle. In the generator, thermal energy is added and refrigerant boils off the solution.

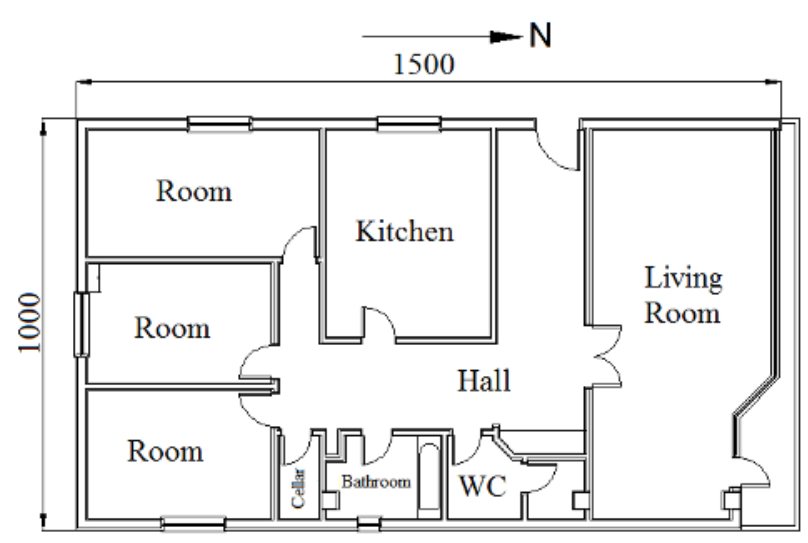

Fig. 1. Plan of the detached house for calculation.

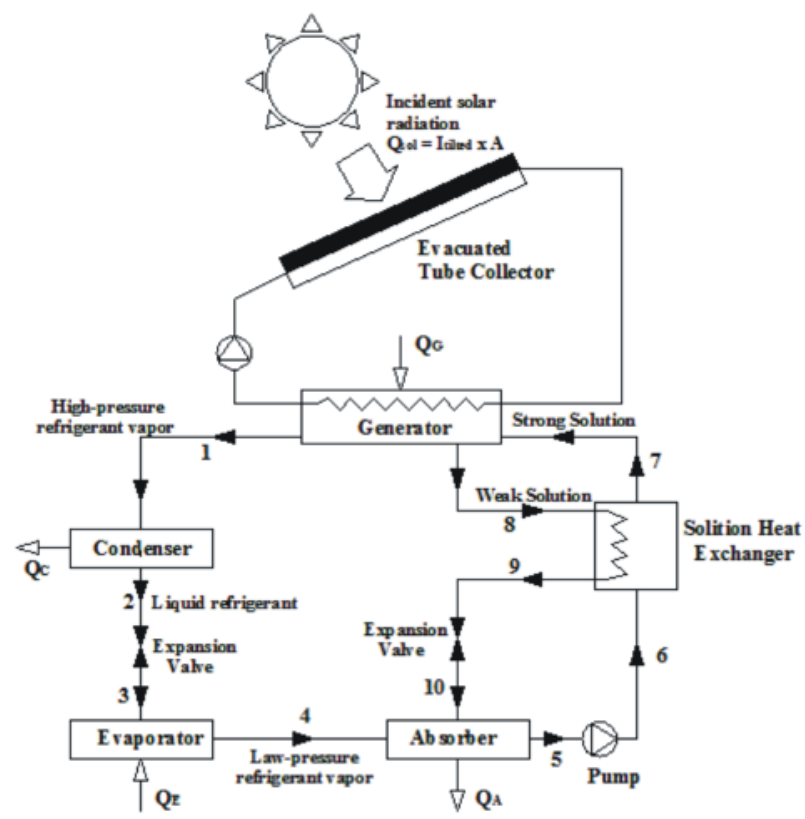

Fig. 2. Schematic view of solar absorption refrigeration system [12].

The refrigerant vapor (1) flows to the condenser, where heat is rejected as the refrigerant condenses. Highpressure liquid refrigerant (2) from the condenser passes into the evaporator (4) through an expansion valve (3) that reduces the pressure of the refrigerant to the low pressure existing in the evaporator. In the evaporator, the heat from the evaporator load evaporates the refrigerant $\mathrm{NH}_{3}$, which flows into the absorber (4). A small portion of the refrigerant leaves the evaporator as liquid spillover. At the generator exit (8), the steam consists of absorbentrefrigerant solution, which is cooled in the heat exchanger. The weak solution (5) is pumped to the generator pressure (7), and the refrigerant in it is boiled off in the generator. The remaining solution (8) flows back to the absorber and, thus, completes the cycle. In order to improve system performance, the solution heat exchanger is included in the cycle [12-20]. Due to high efficiency at high temperature, the evacuated tube solar collector type has been chosen as it can provide good performance at the high temperature required by the absorption system as stated by Assilzadeh et al [21]. 


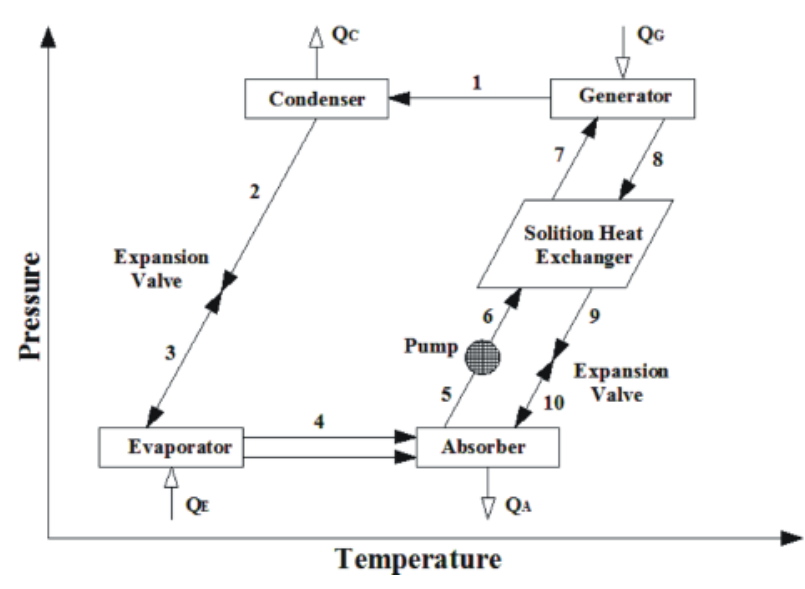

Fig. 3. Pressure-temperature diagram of solar absorption refrigeration system [22].

In the model shown in figure $3, \mathrm{Q}_{\mathrm{G}}$ is the heat input rate from the heat source to the generator, $\mathrm{Q}_{\mathrm{C}}$ and $\mathrm{Q}_{\mathrm{A}}$ are the heat rejection rates from condenser and absorber to the heat sinks, respectively, and $\mathrm{Q}_{\mathrm{E}}$ is the heat input rate from the cooling load to the evaporator.

Some assumptions for thermodynamic analysis of the absorption cooling system are as follows [23]:

- There are steady-state conditions.

- Evaporator temperature is assumed as $10{ }^{\circ} \mathrm{C}$ and condenser temperature is assumed $10{ }^{\circ} \mathrm{C}$ higher than atmospheric air temperature for each stage.

- Generator and condenser pressures are saturation pressure of the refrigerant which corresponds condensation temperature.

- There is saturated refrigerant at the condenser and evaporator outlets.

- Refrigerant vapor's temperature and pressure left from generator are equal to generator's temperature and pressure.

- Refrigerant separated from condenser is saturated liquid basis $\left(\mathrm{x}_{2}=0\right)$.

- Refrigerant separated from evaporator is saturated vapor basis $\left(\mathrm{x}_{4}=1\right)$.

- Pressure drops and heat losses in components and tubes are negligible.

- The work input into the system is disregarded, because pump work is too small.

- Pump is isentropic.

- The condenser and the absorber are cooled by the same source so the absorber outlet temperature is equal to the condenser outlet temperature $\left(T_{5}=T_{2}\right)$.

- The heat exchanger's effectiveness is assumed to be $60 \%$.

For the thermodynamic analysis of the absorption system, the principles of mass conservation and the first and second laws of thermodynamics are applied to each component of the system. Each component can be treated as a control volume with inlet and outlet streams, heat transfer and work interactions. In the system, mass conservation includes the mass balance of each material of the solution. The governing equations of mass and type of material conservation for a steady-state and steadyflow system are given below [24-25]:

$$
\sum m_{i}=\sum m_{o}
$$

$m_{i}(\mathrm{~kg} / \mathrm{s})$ and $m_{o}(\mathrm{~kg} / \mathrm{s})$ are the amount of inlet mass and the outlet mass flow rates.

The first law of thermodynamics:

$$
\sum Q-\sum W=\sum H_{o}-\sum H_{i}
$$

$\mathrm{Q}(\mathrm{kW}), \mathrm{W}(\mathrm{kW}), H_{o}(\mathrm{~kW})$ and $H_{i}(\mathrm{~kW})$ express the amount of heat rate taken or given to the system, the amount of work taken or given, outlet enthalpy and inlet enthalpy.

A mass flow ratio $(f)$ is used as follows;

$$
f=\frac{m_{7}}{m_{1}}
$$

At the generator, total mass balance was calculated as follows;

$$
\begin{gathered}
\dot{m}_{7}=\dot{m}_{8}+\dot{m}_{1} \\
\dot{m}_{7} \cdot x_{7}=\dot{m}_{8} \cdot x_{8}+\dot{m}_{1}
\end{gathered}
$$

From equations (4) and (5);

$$
f=\frac{1-x_{8}}{x_{7}-x_{8}}
$$

Both sides are divided to $m_{1}$ in equation (4);

$$
\frac{\dot{m}_{7}}{\dot{m}_{1}}=\frac{\dot{m}_{8}}{\dot{m}_{1}}+1 \quad \Rightarrow \quad \frac{\dot{m}_{8}}{\dot{m_{1}}}=f-1
$$

The first law of thermodynamics for the generator and from equation (2);

$$
\begin{gathered}
Q_{G}=\dot{m}_{1} \cdot h_{1}+\dot{m}_{8} \cdot h_{8}-\dot{m}_{7} \cdot h_{7} \\
q_{G}=\frac{Q_{G}}{\dot{m_{1}}}=h_{1}+(f-1) \cdot h_{8}-f \cdot h_{7}
\end{gathered}
$$

At the condenser, total mass balance and energy balance were calculated as follows;

$$
Q_{C}=\dot{m}_{2} \cdot h_{2}-\dot{m}_{1} \cdot h_{1}
$$

$m_{1}=m_{2}$ and from equation (10); 


$$
q_{C}=h_{2}-h_{1}
$$

At the evaporator, mass balance and energy balance were determined as follows;

$$
\begin{aligned}
& Q_{E}=\dot{m}_{4} \cdot h_{4}-\dot{m}_{3} \cdot h_{3} \\
& \dot{m}_{1}=\dot{m}_{3}=\dot{m}_{4} \text { and from equation (12); } \\
& q_{E}=h_{4}-h_{3}
\end{aligned}
$$

At the absorber, mass balance and energy balance were given as follows;

$$
Q_{A}=\dot{m}_{5} \cdot h_{5}-\dot{m}_{4} \cdot h_{4}-\dot{m}_{10} \cdot h_{10}
$$

$m_{1}=m_{4}, \quad m_{7}=m_{5} ; \quad m_{8}=m_{10} \quad$ and from equation (14);

$$
q_{A}=f \cdot h_{5}-h_{4}-(f-1) \cdot h_{10}
$$

From the cooling load and the equation (13), flow rate $\left(m_{1}\right)$ can be calculated and it is multiplied by specific heat to calculate total heat capacities.

According to the assumptions the energy balance can be written as [26]:

$$
Q_{C}+Q_{A}=Q_{G}+Q_{E}
$$

The cooling coefficient of performance (COP) of the absorption system is defined as the heat load in the evaporator per unit of heat load in the generator and is obtained by: [23, 27]:

$$
C O P=\frac{Q_{E}}{Q_{G}}
$$

The ideal cooling coefficient of performance of the absorption system is defined with equation (18);

$$
C O P_{\text {ideal }}=\frac{T_{E}}{T_{G}}\left(\frac{T_{G}-T_{C}}{T_{C}-T_{E}}\right)
$$

Evacuated heat pipe tubes are composed of multiple evacuated glass tubes each containing an absorber plate fused to a heat pipe as shown in figure 4. They use compressed liquid or liquid-vapor phase change materials to transfer heat at high efficiency. Each tube contains a glass outer tube and inner glass or metal tube attached to a fin as the absorber. Air is removed, or evacuated, from the space between the two tubes to form a vacuum, which eliminates conductive and convective heat losses as recorded by Kalogirou [26, 27], Stepherd [28] and Beggs [29].

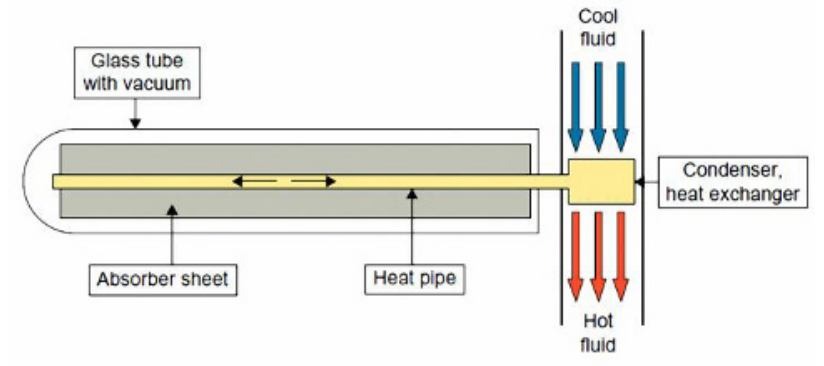

Fig. 4. Schematic view of evacuated tube collector [29].

As seen in figure 2, a solar collector receives solar radiation $\mathrm{Q}_{\text {solar }}(\mathrm{kW})$ that is product of the surface area $\mathrm{A}$ $\left(\mathrm{m}^{2}\right)$, and the solar radiation perpendicular to the tilted surface $\mathrm{I}_{\text {tilted }}\left(\mathrm{kW} / \mathrm{m}^{2}\right)$ from the sun and supplies $\mathrm{Q}_{\text {sol-gen }}$ $(\mathrm{kW})$ to a generator. It is assumed for the calculation that the evacuated solar collector surface is placed with tilted angle of $23^{\circ}$ degree and oriented to the south direction. The solar radiation production on collector surface area and the heat output from solar collectors can be determined using the Hottel-Whillier equation [12, 30,31]:

$$
Q_{\text {solar }}=I_{\text {titled }} \cdot A
$$

$$
Q_{\text {sol-gen }}=F \cdot A \cdot\left[(\tau \cdot \alpha) \cdot I_{\text {titled }}-U\left(T_{W}-T_{A}\right)\right]
$$

where $\tau$ is the transmission coefficient, $\alpha$ is the absorption coefficient, $\mathrm{U}$ is the overall heat transfer coefficient $\left(\mathrm{W} / \mathrm{m}^{2} \mathrm{~K}\right), \mathrm{F}$ is the solar-collector efficiency factor, $\mathrm{T}_{\mathrm{W}}$ is the mean water temperature $\left({ }^{\circ} \mathrm{C}\right)$ and $\mathrm{T}_{\mathrm{A}}$ is the ambient air temperature $\left({ }^{\circ} \mathrm{C}\right)$.

The ratio of supply heat $\mathrm{Q}_{\text {sol-gen }}$ to the solar radiation production $\mathrm{Q}_{\text {sol }}$ is defined as the thermal efficiency of a solar thermal collector $\eta$ used for the calculation of nominal efficiency. [12]:

$$
\begin{gathered}
\eta=\frac{Q_{\text {sol-gen }}}{Q_{\text {solar }}} \\
\eta=F\left[(\tau \alpha)-\frac{U\left(T_{W}-T_{A}\right)}{I_{\text {titled }}}\right]
\end{gathered}
$$

Where, the transmission-absorption coefficient $\tau \alpha$ and the overall heat transfer coefficient $U$ are considered as 0.86 and $0.8 \mathrm{~W} / \mathrm{m}^{2 \circ} \mathrm{C}$, respectively [32].

In the present system, evacuated tube collector is preferred due to its higher thermal efficiency comparing to the flat type solar collector. Generator temperature is taken as $90{ }^{\circ} \mathrm{C}, 100{ }^{\circ} \mathrm{C}, 110{ }^{\circ} \mathrm{C}, 120{ }^{\circ} \mathrm{C}$ and $130{ }^{\circ} \mathrm{C}$ for the analysis.

\section{Results and Discussion}

The obtained results for Mugla, Antalya and Mersin provinces are graphically given in figures 5-11. The maximum daily total radiation data were calculated as $7173 \mathrm{~W} / \mathrm{m}^{2}$ day on July $15,7277 \mathrm{~W} / \mathrm{m}^{2}$ day on July 19 and $7231 \mathrm{~W} / \mathrm{m}^{2}$ day on July 19 for Mersin, Antalya and 
Mugla, respectively on the $23^{\circ}$ tilted and oriented toward south surface, and its daily variation is presented in figure 5. As seen solar energy is only available between 7:00 and 18:00. The maximum hourly radiation values were calculated as $880.39 \mathrm{~W} / \mathrm{m}^{2}$ between 11:00-12:00, 845.89 $\mathrm{W} / \mathrm{m}^{2}$ between 12:00-13:00 and $850.44 \mathrm{~W} / \mathrm{m}^{2}$ between 12:00-13:00 for Mersin, Antalya and Mugla, respectively. All calculations and graphs are drawn for these hours and days.

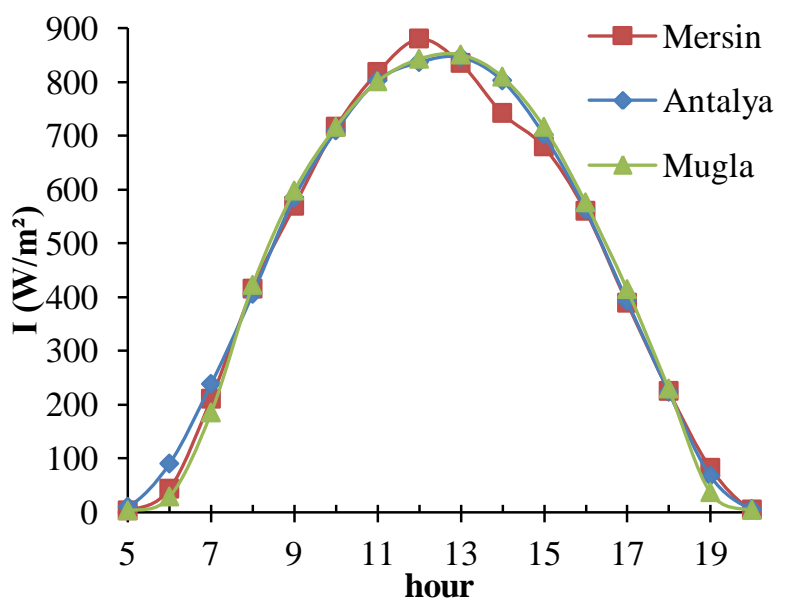

Fig. 5. Daily variation of mean solar irradiation along the years 1998-2008 for the maximum values at $23^{\circ}$ tilted surface.

For a constant effectiveness of $60 \%$ at the heat exchanger, an optimum temperature is determined to be used at the generator, while higher and lower temperature decrease the system COP. For this analysis, generator temperature value was found to be as $\mathrm{T}_{\mathrm{G}}=110^{\circ} \mathrm{C}$ for all provinces as seen in figure 8 . Figure 6 displays the variation of $\mathrm{COP}$ values at different generator temperatures for Antalya province. Although $110^{\circ} \mathrm{C}$ generator temperature provides a bit lower $\mathrm{COP}$ at morning and evening time, it is higher than all at noon time which solar radiation (figure 5), cooling load (figure 9) and atmospheric air temperature (figure 7) at about their maximum values.

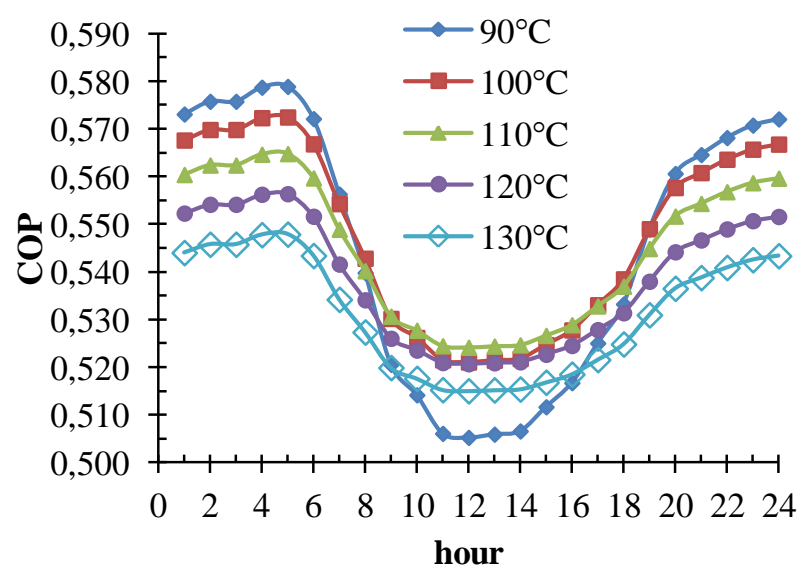

Fig. 6. Hourly variation of the COP for five different generator temperatures for Antalya on July 19.

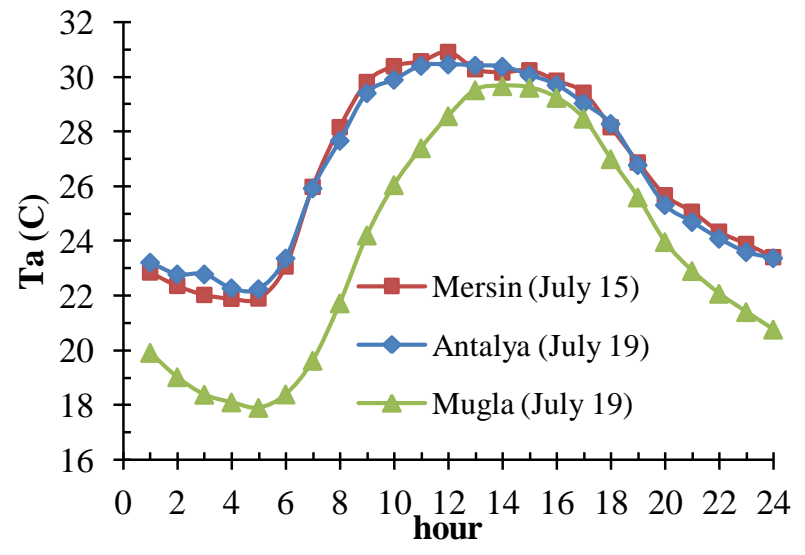

Fig. 7. Variation of atmospheric air temperature for considered days.

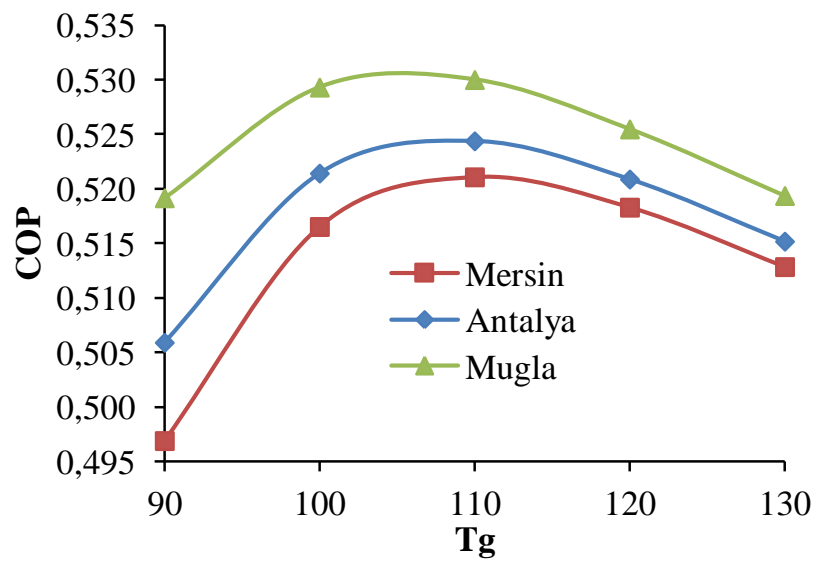

Fig. 8. COP variation as a function of the generator temperature for Mersin, Antalya and Mugla.

The COP values are determined from the obtained results that the highest $\mathrm{COP}$ and its time yield 0.530 at 13:00, 0.524 at 13:00 and 0.521 at 12:00 for Mugla, Antalya and Mersin, respectively as seen in figure 8. It is found that $\mathrm{T}_{\mathrm{G}}=110{ }^{\circ} \mathrm{C}$ is the optimum generator temperature for all provinces (figure 8). Variation of the cooling load of the sample building having $150 \mathrm{~m}^{2}$ floor is given in figure 9. It is found that cooling load demands of the house at different cities are strong function of temperature, radiation and time of the day and it is in the range of 3.08-11.15 kW for Mersin, 2.93-11.18 kW for Antalya and 2.14-11.29 kW for Mugla, respectively. Variation of necessary collector surface area $\mathrm{T}_{\mathrm{G}}=110{ }^{\circ} \mathrm{C}$ for the highest radiation occurred days is presented in figure 10. As seen it decreases with increasing solar radiation around noon. For this simulation, necessary collector area is chosen according to the highest cooling demand. Because, at morning and evening hours due to the lower solar irradiation necessary collector areas and cost of the solar-absorption cooling system become extremely high. Therefore, mean collector surface areas for each province is calculated with respect to the values between 9:00 and 16:00 which are enough for the maximum cooling need time during this period. For this purpose, the selected collector areas at $110{ }^{\circ} \mathrm{C}$ generator temperature are $47 \mathrm{~m}^{2}, 46 \mathrm{~m}^{2}$ and $45 \mathrm{~m}^{2}$ for Antalya Mersin and Mugla, respectively. 


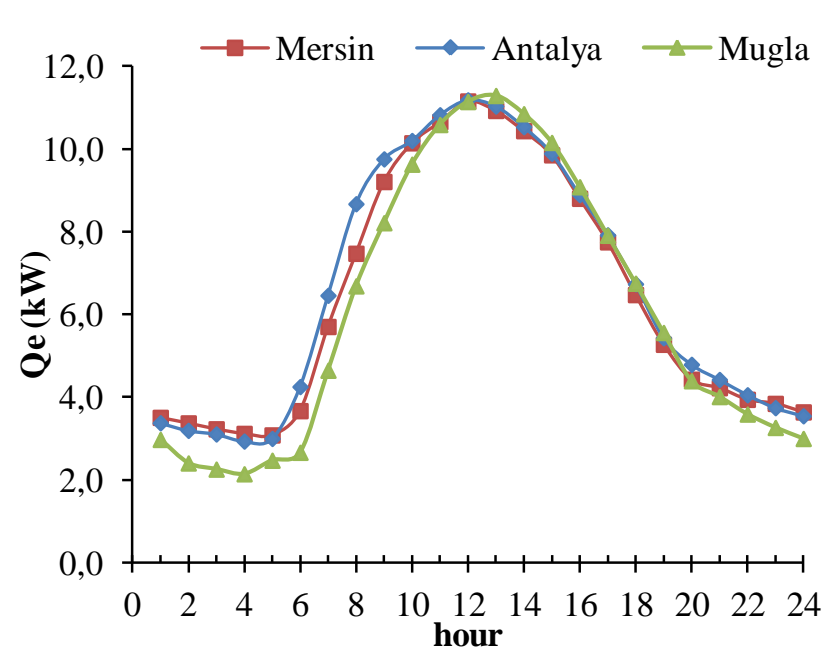

Fig. 9. Hourly variation of cooling load during maximum radiation occurred days.

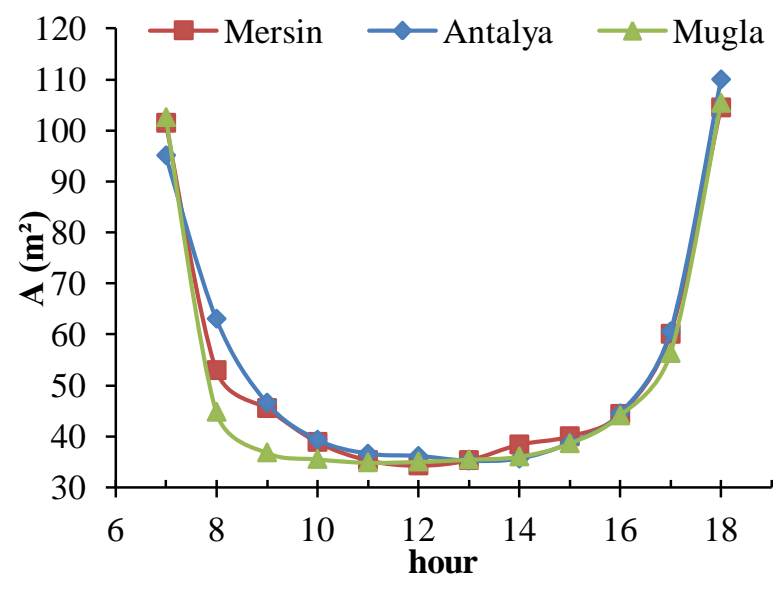

Fig. 10. Daily variation of needed collector area during the maximum radiation occurred days for different provinces at $\mathrm{T}_{\mathrm{G}}=110^{\circ} \mathrm{C}$.

Daily variations of thermal efficiency of the evacuated solar collector for the three provinces at optimum generator temperature $110{ }^{\circ} \mathrm{C}$ is presented in Figure 11. Higher thermal efficiency occurs when the generator temperature equal to $110{ }^{\circ} \mathrm{C}$ similar to the COP trends.

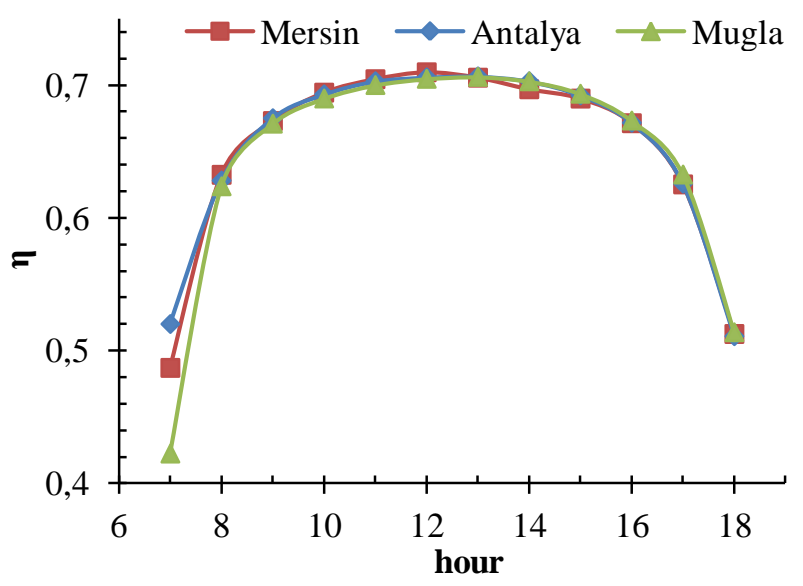

Fig. 11. Hourly variation of thermal efficiency of the evacuated solar collectors at $\mathrm{T}_{\mathrm{G}}=110^{\circ} \mathrm{C}$.

\section{Conclusions}

In this study, the first law of thermodynamics is applied to a solar powered absorption cooling system designed for a detached house with $150 \mathrm{~m}^{2}$ floor area in south coast regions of Turkey. The COP, thermal efficiency, cooling load, necessary panel areas for each provinces are calculated from the thermodynamic properties of the working fluids at various operating conditions by using the developed mathematical model.

- Maximum daily total radiation data were calculated by using meteorological data as 7173 $\mathrm{W} / \mathrm{m}^{2}$ day on July $15,7277 \mathrm{~W} / \mathrm{m}^{2}$ day on July 19 and $7231 \mathrm{~W} / \mathrm{m}^{2}$ day on July 19 for Mersin, Antalya and Mugla, respectively on the $23^{\circ}$ tilted panel surface.

- The results show that COP of the cycle increases with increasing generator temperature to $110^{\circ} \mathrm{C}$, and then it decreases with increasing temperatures. Therefore, the optimum generator temperature for the proposed system is $110^{\circ} \mathrm{C}$.

- When the evaporation temperature is maintained at $10^{\circ} \mathrm{C}$, the maximum COP values of cooling systems are in the range of 0.521 and 0.530 for maximum radiation occurred time of the day in the provinces.

- As solar radiation strength and the atmospheric air temperatures increase, the COP values decreases.

- The necessary evacuated tube collector area for the different provinces were found in the range of $45 \mathrm{~m}^{2}$ to $47 \mathrm{~m}^{2}$.

- Higher thermal efficiency occurs 0.706, 0.709 and 0.706 for Antalya, Mersin and Mugla, respectively when the generator temperature is equal to $110^{\circ} \mathrm{C}$.

Absorption refrigeration systems are more economical than vapor compression systems, since in the previous one heat energy is used rather than electrical. In lithium bromide-water system it is not possible to cool below $0^{\circ} \mathrm{C}$; however, systems with ammonia-water $\left(\mathrm{NH}_{3}-\mathrm{H}_{2} \mathrm{O}\right)$ solution have larger temperature intervals. Hot water or waste steam can also be used as a energy source, and it has been recently applied for cooling purposes. The main disadvantages of the absorption system are that higher investment cost and lack of very low evaporator temperature like conventional refrigeration machines.

\section{Acknowledgements}

The authors would like to acknowledge Selcuk University's Scientific Research Project Contract No: 12701749.

\section{References}

1. Q.G. Lin, G.H. Huang, B. Bass, X.S. Qin, Energy Policy 37 (3) 868-878 (2009)

2. Y.P. Cai, G.H. Huang, Z.F. Yang, Q. Tan, Applied Energy 86 (4) 480-495 (2009)

3. J.T. McMullan, International Journal of Refrigeration 25, 89-99 (2002) 
4. I. Atmaca, A. Yigit, Renewable Energy, 28, Issue 8, Pages 1277-1293 (2003)

5. G. Grossman, Solar Energy 72 (1), 53-62 (2002)

6. F., Ziegler, International Journal of Refrigeration 25, 450-459 (2002)

7. H.M. Henning, Applied Thermal Engineering 27, 1734-1749 (2007)

8. A. Lecuona, R. Ventas, M. Venegas, A. Zacarías, R. Salgado, Solar Energy 83 1806-1814 (2009)

9. S. Kalogirou, Recent Patents on Mechanical Engineering, 1, 58-64 (2008)

10. L. Saylan, O. Sen, H. Toros, A. Arisoy, Energy Conversion and Management 43 1829-1837 (2002)

11. A. Sözen, M. Arcaklioglu, E. Özalp, G. Kanit, Applied Energy, 77, 273-286 (2004)

12. M. Ozgoren, M. Bilgili, O. Babayigit, Applied Thermal Engineering, 40, 80-90 (2012)

13. O. Babayigit, M. Ozgoren, M. H. Aksoy, International Scientific Conference, Gabrovo, Bulgaria, 392-399 (2011)

14. K.F. Fong, T.T. Chow, C.K. Lee, Z. Lin, L.S. Chan, Energy and Buildings, 42, Issue 12, December, 2386-2399 (2010)

15. B. H. Gebreslassie, G. Guillén-Gosálbez, L. Jiménez, D. Boer, Applied Thermal Engineering, 29, Issues 17-18, December 2009, 3491-3500 (2009)

16. C. Monné, S. Alonso, F. Palacín, L. Serra, Applied Thermal Engineering, 31, Issue 1, January, 28-35 (2011)

17. J.R. García Cascales, F. Vera García, J.M. Cano Izquierdo, J.P. Delgado Marín, R. Martínez Sánchez, Applied Thermal Engineering. 31, 112-118 (2011)

18. F.C. McQuiston, J.D. Parker, J.D. Spitler, Heating Ventilating and Air Conditioning Analysis and Design, 5th Ed. New York: John Wiley\&Sons (2000)

19. ASHRAE Fundamentals Handbook, Nonresidential Cooling And Heating Load Calculation Procedures, Atlanta, USA: American Society of Heating, Refrigerating and Air-Conditioning Engineers; Chapter 29 (2001)

20. A. Bula, D. Herrera, L.F. Navarro, A. Lesme Corredor, Heat Exchanger Conferencia Internacional en: Modelado, Simulación Redes Neuronales MSNN (2000)

21. F. Assilzadeh, S.A. Kalogirou, Y. Ali, K. Sopian, Renewable Energy, 30, 1143-1159 (2005)

22. O. Kizilkan, A. Sencan, S.A. Kalogirou, Chem. Eng. Process, 46, 12, 1376-1384 (2007)

23. R. Yamankaradeniz, I. Horuz, O. Kaynakli, S. Coskun, N. Yamankaradeniz, Refrigeration Techniques and Heat Pump Applications, second ed., Dora Publication Company, Bursa, Turkey, (in Turkish) (2009)

24. O. Marc, J.P. Praene, A. Bastide, F. Lucas, Applied Thermal Engineering, 31, 268-277 (2011)

25. R. Gomri, Int. J. of Thermal \& Environmental Engineering, 2, No. 1 35-40 (2011)

26. S.A. Kalogirou, Recent Patents on Engineering, Volume 1, 23-33 (2007)

27. S.A. Kalogirou, Progress in Energy and Combustion Science, 30, 231-295 (2004)
28. W. Shepherd, D.W. Shepherd, Energy studies, Imperial College Press; London (2005)

29. C. Beggs, Energy: Management, Supply and Conservation Linacre House, Jordan Hill, Oxford, Butterwot-Heinemann Second Edition (2009)

30. D.S. Kim, C.A, International Journal of Refrigeration, 31, 3-15 (2008)

31. H.K. Ersoy, S. Yalcin, R. Yapici, M. Ozgoren, Applied Energy, 84, 971-983 (2007)

32. J.A. Duffie, W.A. Beckman, Solar Engineering of Thermal Processes, New York, (1980) 